\title{
Dificuldades de professoras principiantes no processo de ensino e aprendizagem dos conteúdos matemáticos
}

\author{
Klinger Teodoro Ciríaco* \\ Gislaine Aparecida Puton Zortêa**
}

\begin{abstract}
Resumo
Relatamos uma pesquisa que buscou compreender dificuldades nos anos iniciais da docência no ensino de Matemática por professoras egressas da Pedagogia. Os dados foram coletados a partir de entrevistas semiestruturadas com duas docentes e informações da ementa da disciplina que abordou conteúdos matemáticos na formação inicial. A metodologia do estudo é qualitativa e a análise ocorreu à luz de um referencial teórico que contemplou questões ligadas à formação matemática das professoras e o começo da carreira. Identificamos problemas no conhecimento específico dos conteúdos matemáticos no decorrer do curso de formação inicial, o que pode acarretar em desafios na iniciação profissional.
\end{abstract}

Palavras-chave: Formação inicial; Início da docência; Conteúdos matemáticos.

\section{Teaching beginners difficulties in the process of teaching of contents mathematical}

\section{Abstract}

We report a study that sought to understand difficulties in the early years of teaching in the teaching of mathematics by teacher's graduates of Pedagogy. Data were collected from semi-structured interviews with two teachers and menu information of discipline addressed mathematical content in the initial training. The methodology of the study is qualitative and the analysis took place in light of a theoretical framework that included questions related to mathematical training of teachers and career start. We identify problems in specific knowledge of the mathematical content during the initial training course, which may result in challenges in professional training.

Keywords: Basic training; Beginning of teaching; Mathematical contents.

\section{Introdução}

Estudos vêm demonstrando que a área do conhecimento matemático é, por vezes, um desafio para os professores licenciados em Pedagogia, uma vez que a formação inicial para o ensino dos conteúdos matemáticos apresenta-se de modo fragmentada e superficial (CURI, 2004).

Desse modo, a necessidade de conhecer de forma abrangente esse assunto surgiu em decorrência da participação no Grupo de Estudos e Pesquisas sobre Início da Docência e Ensino de Matemática - GEPIDEM/UFMS/CNPq - em ações voltadas para estudos e reflexões sobre os problemas da formação inicial para o ensino e aprendizagem dos conceitos escolares, como também questões ligadas ao professor iniciante em diferentes níveis de atuação com base na pesquisa institucional cadastrada na PROPP/UFMS.

A participação no referido grupo, fez-nos observar que a literatura especializada na área vem demonstrando que vários cursos de formação inicial $^{1}$ trabalham apenas embasamentos metodológicos e não se atentam para o conhecimento específico da Matemática.

\footnotetext{
*Endereço eletrônico: klingerufms@ @otmail.com

*** Endereço eletrônico: gi.zortea@ outlook.com
}

Nessa perspectiva, tendo em vista que quando formados deparamos com os dilemas no começo da carreira e vivenciamos, com isso, o desafio de ensinar aquilo que nem sempre aprendemos, emergiram algumas questões que foram centrais para a realização do estudo, a saber: Qual a formação para o ensino de Matemática obtida no curso de licenciatura em Pedagogia? Que saberes professores novatos mobilizam no processo do aprender a ensinar os conceitos matemáticos? Enfim, que abordagens metodológicas são adotadas para o ensino desses conteúdos?

Nesse sentido, a presente temática de estudos surge da necessidade em pesquisar como professores iniciantes lidam com $\mathrm{o}$ saber matemático durante os primeiros anos da carreira docente, assim como quais recursos utilizam na perspectiva de trabalho com essa disciplina nos anos iniciais do Ensino Fundamental na rede municipal de educação de Naviraí/MS.

Em suma, essa pesquisa procurou referenciais teórico-metodológicos de atuação no ensino de Matemática pela via da prática docente de Pedagogas recém-formadas com o objetivo de verificar como o ensino dessa área do conhecimento 
é realizado no período de iniciação à docência.

Por fim, acreditamos que os estudos dos desafios presentes na prática de professores iniciantes durante as aulas de Matemática podem fornecer pistas para a compreensão de medidas a serem adotadas para a superação dos dilemas decorrentes da inserção na carreira. Ainda, com base na pesquisa, percebemos que podemos contribuir apontando, a partir dos dados empíricos, formas de trabalho alternativo para ensinar conteúdos matemáticos e em como superar o primeiro impacto causado pelo início da carreira docente.

\section{Formação de professores e ingresso na carreira: algumas características e problemas}

A escolha profissional é uma questão muito difícil, pois é nesse momento que o aluno se vê em um dilema que pode modificar toda sua vida ao optar por uma carreira. Huberman (1995, p. 40), contribui com a discussão, ao descrever que não é fácil escolher e firmar o compromisso com uma determinada carreira, uma vez que é "[...] a escolha de uma identidade profissional, e este acto (escolher e renunciar) representa justamente a transição da adolescência, em que "tudo é possível" para a vida adulta, em que os compromissos surgem mais carregados de conseqüências".

Contudo, geralmente, o perfil dos alunos que ingressam nos cursos de licenciaturas são pessoas que fazem essa opção pelo fato destes terem pouca concorrência para o ingresso no Ensino Superior, bem como referem-se a uma parcela significativa da população brasileira de baixa renda e provêm a maioria da escola pública (GATTI, 2010).

Valle (2006, p. 181), ao escrever sobre a carreira do magistério enquanto uma escolha profissional deliberada, afirma que "[...] a carreira docente se torna pouco atrativa, pois, apesar de exigir um enorme investimento pessoal e familiar (diplomas e aprovação em concursos), oferece um futuro profissional bastante incerto, baixos salários, limitadas possibilidades de ascensão pessoal [...]”.

Nessa direção, o que acontece é que alguns professores acabam tendo maior prestígio e melhores salários fora da sala de aula e, como consequência disso, abandonam a carreira docente por se tratar de um campo desvalorizado e desgastante quando comparado com o reconhecimento profissional perante a sociedade.

Pimenta (2005, p. 07), enriquece nosso entendimento, ao apontar que tais problemas são decorrentes das limitações dos programas de formação docente "[...] que historicamente acumula índices precários devido a formação aligeirada e muitas vezes frágil teórica e praticamente, em cursos nos quais a didática e as metodologias são meros discursos técnicos sobre o ensinar."

Desse modo, muito do que se aprende na profissão docente acaba por ser oriundo do saber da prática no contato com o contexto do trabalho pedagógico. Assim, os professores quando ingressam na carreira iniciam um processo de aprendizagem da docência via exploração, no tatear constante, o que resulta em saberes experienciais (TARDIF, 2007). Tal fato demonstra o quanto o momento da iniciação é decisivo para a permanência na profissão, como também pode ser considerado um período de aprendizagens intensas.

Sendo assim, ao ingressar na carreira docente o professor busca o equilíbrio para que possa "sobreviver" ao início conturbado do exercício da docência. Souza (2009) considera que é no começo da carreira que o professor se vê a mercê da sorte, sem ter com quem compartilhar suas dificuldades. Com isso, a autora afirma ainda que por não ter experiência profissional, “[...] 0 professor acaba apoiando sua prática em ações que vivenciou na época de estudante, reproduzindo a prática de seus antigos professores [...]" (SOUZA, 2009, p. 37).

Embora o início da carreira docente seja difícil, essa é uma etapa importante para o professor principiante por se configurar como sendo um período de transição e construção da sua identidade com a profissão. Alguns estudos entram num consenso de que esse momento é dado como sofrido, pois além de vivenciar as dificuldades encontradas ao ensinar conteúdos que por muitas vezes são pouco compreendidos pelo próprio professor, ainda deve lidar com a organização das escolas e o comportamento dos alunos (LIMA, 1996; GUARNIERI, 1996).

Nesse contexto, o período de iniciação é dotado de características próprias que marcam estilos de docência. São muitos os problemas que o professor encontra nessa fase de sua vida e, de acordo com Veenman (1984), o mais complexo refere-se ao "choque de realidade", sentimento esse decorrente das expectativas iniciais em relação à carreira e a realidade vivenciada nas escolas.

Por isso é necessário que os cursos de formação inicial deem apoio para que o professor em formação construa bases de iniciação 
profissional. Feimam (2001, apud MARCELO GARCÍA, 2010, p.14) chama "[...] a atenção sobre o divórcio que existe entre a formação inicial e a realidade escolar". Assim, compreendemos que seja papel da formação inicial contribuir para o desenvolvimento profissional dos professores iniciantes na medida em que a mesma leva em consideração, no decorrer do curso de licenciatura, as práticas escolares em sua grade curricular como um componente fundamental.

Huberman (1995) apresenta-nos um quadro teórico-metodológico relevante ao descrever as fases do ciclo de vida profissional dos professores. A contribuição do autor apresenta-se como de grande relevância para a literatura da área na medida em que ele caracteriza a docência em fases, sendo elas: a) a entrada na carreira (de 1 a 3 anos de profissão); b) estabilização (de 4 a 6 anos); c) diversificação e experimentação (de 7 a 25 anos); d) serenidade e distanciamento afetivo (de 25 a 35 anos) e; e) preparação para a aposentadoria (de 35 a 40 anos de carreira).

Em nossa pesquisa, centramos a discussão na descrição da fase de entrada na carreira na tentativa de caracterizar os desafios do trabalho pedagógico no ensino de Matemática, conforme mencionado na introdução. Logo, o início da aprendizagem profissional pode ser considerado complexo e marcado por estágios que traduzem sentimentos de "sobrevivências" e "descobertas".

A partir dessa concepção é possível conhecer a realidade da sala de aula e dos alunos. Segundo Huberman (1995), é nesse período de descoberta que o aluno-professor toma para si o "comprometimento definitivo" (p. 39), ou seja, o principiante acaba por se sentir mais seguro das ações de sua prática, pois após a "sobrevivência" ele finalmente tem um reconhecimento como docente e acaba por se sentir mais livre para traçar novos caminhos com maior autonomia, sem ter medo do julgamento dos colegas de profissão.

Marcelo García (2010) esclarece que o conhecimento do conteúdo envolve muito além dos processos metodológicos, ou seja, engloba o conhecimento específico da matéria de ensino (SHULMAN, 1987) e a articulação entre o "como" e "o que" ensinar aos alunos precisa ser a base da aprendizagem nos primeiros anos da docência. Essa situação demonstra que o docente iniciante necessita tanto do apoio institucional quanto dos colegas mais experientes para aprender a ensinar.

Contudo, nem sempre é isso o que observamos. Pesquisas e a própria prática escolar vêm demonstrando, em seus resultados e experiências, que o novato na docência é, muitas vezes, testado como profissional, além de ser avaliado pelos professores mais antigos e a entrada na carreira acaba se tornando um momento marcado por solidão e isolamento, sentimentos esses que são favorecidos pela própria forma da organização escolar (TARDIF, 2007). A configuração dessa realidade se agrava ainda mais quando são atribuídas para os iniciantes as turmas mais difíceis e delegam-lhes toda a responsabilidade pelos índices de desempenho escolar de seus alunos (MARIANO, 2012).

Outra frustração recorrente reside ainda no fato de que os principiantes "[...] descobrem que, na sala dos professores, as discussões fundamentais sobre os princípios educacionais ou sobre as orientações pedagógicas não são realmente importantes" (TARDIF; RAYMOND, 2000, p. 226).

Franco (2000, p. 34) destaca outros problemas oriundos da iniciação à docência durante os primeiros anos de carreira, sendo eles: “[...] 1) problemas em conduzir o processo de ensino e de aprendizagem, considerando as etapas de desenvolvimento de seus alunos e o conteúdo a ser desenvolvido; 2) problemas com a disciplina dos alunos e com a organização da sala de aula".

Sobre as dificuldades da carreira, Marcelo García (2010, p.29) aponta que:

[...] a realidade cotidiana do professorado iniciante nos indica que muitos professores abandonam a profissão e fazem isso por estarem insatisfeitos com seu trabalho devido aos baixos salários, a problemas de disciplina com os alunos, à falta de apoio e poucas oportunidades para participar na tomada de decisões.

Nessa direção, cabe a ressalva da importância de implementar políticas de apoio tanto a inserção na docência quanto a promoção da permanência nessa profissão, ou seja, é preciso a criação de uma política que contribua com a transição do estado de discente para docente, como é o caso de alguns outros países como, por exemplo, Portugal $^{3}$ que, diferentemente do Brasil, há uma política que visa amenizar esse primeiro impacto.

Como pudemos observar são inúmeros os problemas tanto da formação docente quanto dos primeiros anos na carreira. No próximo tópico buscaremos destacar o que dizem alguns estudos sobre a formação matemática do professor polivalente. 


\section{A formação matemática presente no curso de Pedagogia}

Pesquisas $^{4}$ e a própria experiência no contexto da formação inicial de professores demonstram que a Matemática vem sendo apresentada no curso de Pedagogia de maneira fragmentada de forma que não contribui para a formação específica dos acadêmicos em relação aos conteúdos matemáticos que precisam ser iniciados nos primeiros anos de escolarização. Nacarato et al (2004) argumentam que os alunos do curso de Pedagogia não costumam utilizar de estratégias de forma exploratória para resolver problemas ou explicar a maneira de pensar/realizar atividade referente aos conteúdos programados.

Gomes (2006, p.53), em estudos sobre os obstáculos epistemológicos em relação à Matemática, aponta que:

É preciso alterar a relação que os estudantes, futuros professores, estabelecem com a matemática. Se o ensino deve voltar-se para a construção de conhecimento de modo que as crianças sejam encorajadas a solucionar diferentes situações-problemas, é antes necessário que se dê oportunidade aos futuros professores de fazerem o mesmo, pois como poderão encorajar e estimular seus alunos quem nunca teve esta oportunidade em toda sua trajetória escolar?

Para a autora "[...] a mudança não deve ocorrer apenas em torno do currículo, de materiais de apoio, mas, sobretudo, sobre o modo de entender e conceber a matemática [...]" no decorrer da formação inicial.

Vasconcellos (2009), em sua tese de doutorado, ao investigar os saberes mobilizados no início da carreira em relação aos conteúdos matemáticos, constatou que os professores iniciantes quando indagados sobre a disciplina de Matemática presente no curso de Pedagogia revelaram sentimentos negativos de aflição e descontentamento.

Para Gomes (2002, p.364)

[...] a aprendizagem matemática ainda se constitui em um grande problema, tanto para crianças quanto para os professores que estão sendo formados nos cursos de Pedagogia. Isso justifica, muitas vezes, que a própria opção pelo curso seja determinada pela inexistência de matemática em sua grade curricular.
Contudo, no decorrer do tempo a disciplina de Fundamentos e Metodologias do Ensino de Matemática faz-se presente durante o processo formativo e os futuros professores passam a lidar com medos e conflitos decorrentes, muitas vezes, de experiências negativas em relação a essa área do conhecimento.

Logo, temos um grande desafio no curso de Pedagogia, o de desmistificar mitos e equívocos sobre o que seja aprender e ensinar conteúdos matemáticos nos primeiros anos de escolarização, uma vez que esse profissional terá de introduzir os conceitos com as crianças.

Nesse contexto, muitos acadêmicos se veem perdidos e não entendem a complexidade do processo de ensino e aprendizagem da Matemática escolar no curso de formação inicial por se tratar, muitas vezes, de "[...] uma formação centrada em processos metodológicos, desconsiderando os fundamentos da matemática" (NACARATO; MENGALI; PASSOS, 2009, p. 17).

Essa desatenção por parte do curso faz com que o futuro professor não dê a devida importância ao conhecimento matemático, o que acaba por reforçar "[...] uma concepção dominante de que o professor polivalente não precisa "saber Matemática' e que basta saber como ensiná-la" (CURI, 2004, p. 77).

Assim, é preciso compreendermos "[...] a necessidade de a formação inicial oportunizar aos acadêmicos conhecimentos e aprendizagens que beneficiem a construção dos aspectos epistemológicos da disciplina de matemática" (BEDNARCHUK, 2012, p.23).

Como são raramente demonstrados aspectos lúdicos e prazerosos da aprendizagem matemática nos cursos de licenciatura dessa área, alguns professores ainda têm um sentimento de aversão à matéria (CURI, 2004) por não terem domínio necessário para o ensino desses conteúdos. Curi (2005, p. 8), em sua pesquisa de doutorado, analisou 36 instituições e constatou:

[...] a pouca presença de conteúdos matemáticos e de suas didáticas nos currículos dos cursos de Pedagogia. Cabe destacar que a organização da disciplina de Metodologia do Ensino de Matemática, em algumas instituições, era unificada à outra referente aos conteúdos matemáticos. Na maioria, porém, a disciplina tinha caráter mais metodológico, com predominância de temas de caráter mais geral do ensino de Matemática em detrimento de discussões metodológicas sobre temas 
matemáticos previstos para serem desenvolvidos nos anos iniciais do ensino fundamental.

Os dados da tese da autora apontaram que além de ter uma carga horária que varia entre 36 e 120 horas, os cursos trazem nas ementas das disciplinas referenciais sobre jogos e brincadeiras, mostrando o empobrecimento da formação para o ensino de Matemática na Pedagogia.

Bednarchuk (2012), em concordância com Curi (2004), evidencia que o curso de Pedagogia sofre "duras" críticas a respeito da formação de professores que ensinam matemática:

Várias são as críticas destinadas aos cursos de licenciatura em Pedagogia, pois além de possuírem em suas grades curriculares, carga horária mínima para as disciplinas que tratam da formação matemática, as ementas das mesmas se apresentam esvaziadas de aspectos conceituais e conteúdos matemáticos (p. 38).

Seguindo essa mesma linha de raciocínio, Ciríaco e Teixeira (2014, p. 159) evidenciam que:

[...] é preciso que os cursos de Licenciatura em Pedagogia trabalhem referenciais teóricometodológicos dos conteúdos básicos de Matemática e de seu ensino, de maneira que possibilite aos futuros professores refletirem sobre o ensino dos conteúdos dessa área, tanto na Educação Infantil quanto nos Anos Iniciais do Ensino Fundamental.

Nesse entendimento, acreditamos que por ter esse perfil formativo, os professores iniciantes, acabam por carregar ao longo da prática pedagógica resquícios desse déficit e isso pode contribuir para os problemas da aprendizagem de conceitos nos anos iniciais do Ensino Fundamental. Além disso, a formação matemática oportunizada no contexto do curso contribui para o reforço de práticas mecanizadas baseadas em procedimentos de memorização de técnicas, além da forte dependência do livro didático, como menciona Pavanello (2002).

$O$ resultado desse perfil de formação resulta numa prática pedagógica "[...] centrada em cálculos e procedimentos" (NACARATO; MENGALI; PASSOS, 2009, p. 32), que não leva em consideração recomendações tanto de documentos oficiais para o ensino dos conteúdos matemáticos quanto das tendências metodológicas atuais que se baseiam na problematização e resolução de problemas como eixo central do trabalho pedagógico nos anos iniciais do Ensino Fundamental (BRASIL, 1997).

A partir dessa constatação, de que a formação de professores para o ensino de Matemática apresenta-se fragmentada e distante das atuais tendências curriculares da escola, acreditamos que possa existir um bloqueio para a aprendizagem da docência nessa área, uma vez que as experiências das futuras professoras parecem estar atreladas às crenças e concepções negativas que obtiveram ao longo da formação escolar.

Esse fato pode comprometer, de forma significativa, o período de início da docência e resultar em dificuldades epistemológicas em relação aos conteúdos que terão de ensinar, haja vista que as professoras já estão condicionadas ao sentimento de incapacidade sobre o ensino de Matemática.

Sobre essa questão, Nono e Mizukami (2006, p. 340) afirmam que "[...] a formação inicial do professor das primeiras séries tem investido pouco no ensino de matemática, o que reflete nos baixos índices de desempenho dos alunos das séries iniciais do ensino fundamental nessa área em avaliações externas de nível nacional".

Sendo assim, a Matemática torna-se um campo de atuação complexo tanto para quem ensina, quanto para quem aprende. Nono e Mizukami (2006, p. 341) advertem ainda "[...] que nenhum professor consegue criar, planejar, realizar, gerir e avalizar situações didáticas eficazes para aprendizagem sem o domínio de conteúdos específicos das áreas de conhecimento".

Para que esse domínio seja possível é necessária uma apropriação da matéria por parte de quem ensina, ou seja, o professor precisa ter domínio dos procedimentos que regem a área de sua atuação. Com isso, indagamos: como ensinar algo que nem sempre se aprendeu e quais os desafios presentes na organização do trabalho pedagógico com a Matemática nos primeiros anos da docência?

Em suma, é recomendado, de acordo com Nono e Mizukami (2006, p. 347), que os professores novatos "[...] ampliem sua própria competência na resolução de situações-problemas [...]" gerando questões problemas e procurando a forma mais adequada para a resolução, favorecendo o entendimento do aluno ao que diz respeito das matérias propostas.

Por fim, concluímos que ao longo da formação é necessária a construção de esquemas que proporcionem reflexão sobre os conteúdos programados e os métodos de resolução, fazendo com que o futuro professor experiencie a prática do 
aprender e do ensinar.

\section{Delineamento metodológico}

O estudo descrito nesse artigo se inscreve no campo da pesquisa qualitativa em educação com um caráter descritivo-analítico por se tratar de ações que envolveram a participação direta dos pesquisadores no ambiente investigado (LÜDKE; ANDRÉ, 1986).

Bogdan e Biklen (1994) afirmam que:

[...] embora os dados quantitativos recolhidos por outras pessoas (avaliadores, administradores e outros investigadores) possam ser convencionalmente úteis tal como foram descritos, os investigadores qualitativos dispõem-se à recolha de dados quantitativos de forma crítica. Não é que os números por si não tenham valor. Em vez disso, o investigador qualitativo tende a virar o processo de compilação na sua cabeça perguntando-se o que os números dizem acerca das suposições das pessoas que os usam e os compilam. [...] Os investigadores qualitativos são inflexíveis em não tomar os dados quantitativos por seu valor facial (p. 195).

Dessa forma, os dados pertinentes aos objetivos do estudo foram coletados no contexto de uma pesquisa institucional cadastrada na PróReitoria de Pesquisa e Pós-Graduação - PROPP da Universidade Federal de Mato Grosso do Sul/UFMS, câmpus de Naviraí intitulada "Trajetórias formativas de professores iniciantes: o percurso de desenvolvimento profissional $e$ aprendizagem colaborativa da docência em Matemática", coordenada pelo primeiro autor desse texto e que está em andamento desde agosto de 2013 com o objetivo de compreender processos de aprendizagem da docência em um grupo de professoras iniciantes que atuam na rede municipal de educação de Naviraí/MS.

Para tanto, o objetivo geral dessa pesquisa foi compreender as dificuldades encontradas pelas professoras iniciantes no ensino dos conteúdos da Matemática escolar.

Assim, na tentativa de responder o foco do estudo, o trabalho de campo deu-se a partir dos objetivos específicos relacionados no quadro abaixo:

\section{QUADRO 01: Relação entre objetivos específicos e indicadores de análise de dados}

\begin{tabular}{|c|c|}
\hline OBJETIVOS & INDICADORES \\
\hline $\begin{array}{l}\text { - Analisar o percurso do professor para chegar } \\
\text { até a sala de aula, bem como as dificuldades } \\
\text { do começo da carreira; }\end{array}$ & $\begin{array}{l}\text { - Forma de ingresso na docência; } \\
\text { - Acolhida na escola; } \\
\text { - Contato com a sala de aula; }\end{array}$ \\
\hline $\begin{array}{l}\text { - Identificar as abordagens adotadas para o } \\
\text { ensino dos conteúdos matemáticos; }\end{array}$ & $\begin{array}{l}\text { - Compreensão dos conteúdos; } \\
\text { - Metodologia utilizada; }\end{array}$ \\
\hline $\begin{array}{l}\text { - Descrever a formação para o ensino de } \\
\text { Matemática obtida no curso de licenciatura dos } \\
\text { quais as professoras participantes da pesquisa } \\
\text { são egressas. }\end{array}$ & $\begin{array}{l}\text { - Ementas das disciplinas de Matemática dos } \\
\text { cursos de Pedagogia; } \\
\text { - Formação matemática. }\end{array}$ \\
\hline
\end{tabular}

Fonte: Elaborado pelos autores, 2015.

Além disso, alguns instrumentos específicos para a elaboração do estudo envolveram a entrevista semiestruturada, análise documental da ementa da disciplina de fundamentos e metodologias do ensino de Matemática presente nos cursos de licenciatura dos quais as professoras participantes são egressas.

Outro ponto relevante do caráter metodológico refere-se ao aprofundamento em referenciais teóricos que discutem a temática do professor em início de carreira e sua formação para o ensino dos conteúdos matemáticos.
Com isso, o levantamento da tendência investigativa sobre problemas e perspectivas tanto da formação inicial quanto do ingresso na profissão serviu de norte para discussões mais aprofundadas que terão como eixo central caracterizar melhor essa fase da vida do professor, bem como para que pudéssemos problematizar as entrevistas.

$\mathrm{O}$ roteiro de entrevista que subsidiou a análise desse estudo foi composto por questões que buscaram caracterizar os seguintes pontos: a) ingresso na carreira; b) acolhida na escola; c) 
dificuldades com os conteúdos matemáticos e; d) formas de superação.

Para Manzini (1991, p.02) com a entrevista “[...] é possível obter respostas mais precisas do informante, pois o entrevistador pode, além de fazer perguntas complementares, ajudar a expressão adequada do pensamento do entrevistado [...]", ou seja, diferente da entrevista com questionário a entrevista que usaremos permite que seja explorada de forma ampla as questões feitas, além de dar a possibilidade de questionar caso haja dúvida.

Ao final, os dados foram transcritos e analisados com base na elaboração de categorias que visaram atender as expectativas iniciais do estudo, a saber: caracterizar processos de aprendizagem da docência em Matemática nos primeiros anos da carreira tendo em vista levantar as dificuldades das professoras.

\section{Caracterização das professoras participantes da pesquisa}

Dentre os sujeitos da pesquisa institucional mencionada nesta metodologia, utilizamos o critério de trabalhar apenas com duas professoras que atuam em turmas de $3^{\circ}$ ano do Ensino Fundamental, uma vez que o foco deste trabalho encontra-se voltado para os anos iniciais. Assim, essas docentes serão referenciadas por meio de nomes fictícios sob forma de manter o anonimato, sendo elas: Laura e Emma.
Laura possui 27 anos, tem graduação em Pedagogia com Pós-graduação em Educação Infantil e Séries Iniciais, atuava no momento da coleta de dados há um ano na rede municipal de educação local.

Emma tem 32 anos, possui graduação em Normal Superior e Pedagogia, quando contribuiu com a pesquisa tinha três anos de atuação como professora da rede estadual e municipal.

Nesse sentido, após termos o processo de coleta de dados iniciado, tentamos com base na entrevista atender os objetivos inicialmente traçados para o trabalho de campo. O modo de organização desse processo será mais bem detalhado nos próximos tópicos.

\section{Características da formação matemática das professoras iniciantes}

O objetivo desse tópico é apresentar a análise das características da formação matemática no curso de Pedagogia em que as professoras colaboradoras da pesquisa se formaram. Para isso, fizemos um levantamento junto a Instituição de Ensino Superior (IES) particular ${ }^{5}$ de que elas são egressas para ter uma maior compreensão de como os conteúdos matemáticos estão/foram dispostos no curso em questão.

Assim, elaboramos um quadro que demonstra esse perfil formativo:

\section{QUADRO 02: Formação matemática das professoras em início de carreira}

\begin{tabular}{|l|l|l|}
\hline \multicolumn{1}{|c|}{ DISCIPLINA } & \multicolumn{1}{|c|}{ CH } & \multicolumn{1}{c|}{ EMENTA } \\
\hline $\begin{array}{l}\text { Fundamentos e Metodologia } \\
\text { do Ensino de Matemática }\end{array}$ & 80 horas & $\begin{array}{l}\text { Matemática no ensino dos anos iniciais do ensino fundamental: } \\
\text { importância e significado, alternativas metodológicas, seleção e } \\
\text { estruturação dos conteúdos, Geometria intuitiva, números } \\
\text { naturais, o ensino de problemas, materiais e procedimentos } \\
\text { didáticos. Planejamento de ensino da matemática. Analise e uso } \\
\text { dos livros didáticos }\end{array}$ \\
\hline
\end{tabular}

FONTE: Ementa da disciplina de Matemática da IES particular, 2013.

Observando o quadro 02, que descreve aspectos da abordagem matemática no curso de Licenciatura Plena em Pedagogia, podemos ressaltar que o ensino parece, pela escrita do texto, estar mais focado em aspectos metodológicos e, com isso, deixa de lado o ensino específico da Matemática. Essa afirmativa é possível porque a ementa não faz menção às áreas do conhecimento matemático dos anos iniciais, a saber: números e operações, grandezas e medidas, geometria e tratamento da informação.
Ainda nessa análise, foi constatado que as leituras sugeridas pela bibliografia dessa disciplina referem-se à metodologia. São indicados os seguintes autores: Kamii (1984) para abordagem da construção do conceito de número; Dante (2000) ao destacar pontos da resolução de problemas; Cerquetti-Aberkane e Berdonneau (2001) e Panizza (2006) para questões que abordam os princípios dos conteúdos na Educação Infantil, muito embora essa área de atuação do professor não seja mencionada na ementa; Smole (2003) para as relações 
matemáticas e inteligências múltiplas; Nacarato e Lopes (2005) sobre escritas e leituras em matemática, entre outros textos que descrevem abordagens metodológicas de ensino.

Nesse contexto, os professores iniciantes acabam levando para o início de carreira as lacunas formativas decorrentes do curso de Pedagogia.

Reconhecemos a importância do referencial mencionado, contudo, tal disciplina deve levar em consideração a defasagem do professor enquanto aluno e abordar os conteúdos em si, oferecendo-lhe respaldo maior sobre "o que" ensinar, ou seja, é preciso um movimento que torne o conhecimento "de" Matemática mais presente na formação inicial.

Para Curi e Pires (2008, p. 162) “[...] as disciplinas relativas à matemática e seu ensino que constam das grades curriculares dos cursos de pedagogia têm uma carga horária bastante reduzida". Em concordância com as autoras, defendemos o pressuposto de que é preciso a criação de disciplinas voltadas para essa área obedecendo às características de cada segmento de ensino (Educação Infantil e Anos Iniciais).

A ementa traz a discussão apenas sobre a Matemática dos anos iniciais, bem como a importância dela para os alunos, entretanto, não vimos nenhuma menção a Educação Infantil, momento esse que também é possível trabalhar conteúdos matemáticos com as crianças através de brincadeiras, tornando o ato de aprender prazeroso e instigando-as a construção do pensamento lógicomatemático.

Os dados encontrados corroboram com as conclusões de pesquisas sobre a formação matemática do professor como já enfatizaram Curi e Pires (2008, p. 181):

[...] tempo insuficiente, levando-se em conta o que outros estudos revelam: a falta de conhecimentos matemáticos dos professores que atuam nessa etapa inicial da escolaridade; no que se refere às discussões sobre questões de natureza didática e metodológica, a abordagem é bastante simplificada, sem o apoio de fundamentações teóricas nem de resultados de pesquisa na área de educação matemática.

Nacarato, Mengali e Passos (2009) afirmam que os níveis de formação dos professores polivalentes demonstram situação desfavorável quando se trata da Matemática, pois os cursos de Pedagogia não se atentam a essas questões, muitas vezes o professor que fica responsável por essa matéria não está totalmente apto a ela o que acaba ocorrendo, então, é "[...] muitas vezes, uma formação centrada em processos metodológicos, desconsiderando os fundamentos da matemática" (NACARATO; MENGALI; PASSOS, 2009, p. 17).

Sendo assim, mesmo que a disciplina seja bem fundamentada ainda haverá defasagem e fragilidade da organização curricular, o que acaba contribuindo para as dificuldades pedagógicas no início da docência.

\section{Problemas e perspectivas do começo da carreira nas aulas de matemática}

As professoras Emma e Laura ingressaram na carreira docente entre os anos de 2010 e 2012 ambas na rede pública de ensino no município de Naviraí/MS como contratadas e estão na mesma situação funcional até o momento da escrita desse artigo. As razões que as levaram a cursar Pedagogia foram distintas, para Emma o desejo de ser professora foi um sonho de infância, pois sempre brincava de "escolinha" e sentia-se bem nesse espaço imaginário quando criança, bem como buscou aprimorar-se nessa carreira pelo fato de ser a única da família a cursar Ensino Superior.

No caso de Laura, sua primeira opção era o curso de Direito, mas não conseguiu ingressar na universidade desejada e, assim, cursou Pedagogia por também ter afinidades com essa área.

Ambas concluíram a formação superior e esperaram um tempo para ingressar na docência por medo e insegurança, pois se sentiam preocupadas em deixar o emprego onde tinham registro em carteira para assumir uma nova profissão como contratadas, ou seja, a forma de ingresso foi um dado que contribuiu para a entrada na carreira tempos depois da conclusão do curso.

Assim, quando assumiram seus cargos como docentes, elas revelaram alguns desafios presentes na etapa de iniciação à carreira, conforme podemos verificar em seus relatos:

[...] hoje para mim ficou complicado, porque a minha sala, além de eu estar começando, a minha sala não recebeu nada de livro didático, então, eu tive que, por não ter experiência, ter que estar buscando atividade, garimpando atividade [...] Laura.

[...] você ir para a sala só com um método é difícil porque você tem trinta alunos, então, dez pegam o método tradicional, os outros você tem que trabalhar de forma diferenciada, um jogo [...] internet, outro método mesmo [...], 
confecção de material, e eu não conhecia esse lado, então eu passei bastante apurada [...]Emma.

Os relatos das professoras apontam para a falta de apoio pedagógico da escola, no caso de Laura, e as dificuldades com os métodos e materiais para abordagem dos conteúdos curriculares, em relação às vivências de Emma. Esses dados são frequentemente observados em pesquisas anteriores em que foram constatados também elementos semelhantes ao caso descrito (MARIANO, 2012; FREITAS, 2000; SILVEIRA, 2002).

As falas destacadas recaem em situações difíceis em que observamos o descaso pelo professor iniciante e isso nos permite corroborar a conclusão de Silveira (2002) em que a autora descreve o início da docência como avassalador. "A professora é colocada de frente com tudo aquilo com que a escola não está preparada para lidar, e o mecanismo sutil parece ser este: a professora é deixada sozinha, sem apoio" (SILVEIRA, 2002, p. 116-117).

Diante da realidade observada, percebemos que essa problemática pode ir além do espaço da sala de aula como, por exemplo, no contato com os demais professores no momento da socialização profissional do principiante, tendo em vista que muitas vezes o sentimento de solidão é vivenciado nessa fase da carreira, como apontado pelas docentes (TARDIF; RAYMOND, 2000).

Nessa perspectiva, buscamos compreender como foi o contato com os professores mais experientes, ao que obtivemos as seguintes afirmativas:

[...] eu tenho um caderno antigo que elas tinham de exemplo de atividades e busco mais atividades da internet então eu tenho um parâmetro que eu tenho que seria esse caderno [...] eu procuro atividades semelhantes que o que ela trabalhou, era mais ou menos o que ela sabia até onde o aluno podia ir [...] Laura

Tem alguém que me ajuda na hora de desenvolver a atividade que eu coloquei ali [...] é a minha coordenadora de área. Emma

Embora Laura afirme que teve esse apoio das professoras, notamos que as mesmas não estão abertas para o esclarecimento das dúvidas que a professora egressa possui. Tardif (2007), em suas constatações teóricas, corrobora sentimentos da professora quando enfatiza que a grande frustração do professor no início da docência é perceber que nem sempre as reuniões voltadas ao apoio pedagógico de fato não são tão importantes.

Já Emma descreve uma situação um pouco diferente da realidade constatada em muitos estudos sobre essa fase da vida do professor. Como vimos, ela afirma receber apoio de sua coordenadora de área, o que é uma possibilidade remota, pois no estado de Mato Grosso do Sul (MS) até meados de $2013^{6}$ os professores da rede estadual tinham coordenadores de área para Língua Portuguesa e Matemática e o papel destes profissionais era o de contribuir com a prática nessas duas disciplinas. Mesmo com essa ajuda, no caso desta professora, é possível afirmarmos que em relação aos professores mais experientes pouco se obteve de apoio e auxílio nas dificuldades nas aulas de Matemática.

$O$ ingresso na docência e a inserção na escola tende a ser dificultoso, pois muitas vezes o docente não compreende as relações estabelecidas no ambiente de trabalho e tem medo do julgamento que possa sofrer por parte dos mais experientes.

Essa constatação aponta para a fragilidade da formação inicial, em que lhes foram apresentados modelos de salas com alunos ideais e, ao ingressar na sala de aula, evidentemente, sofreram o "choque de realidade" (VEENMAN, 1984). Nesse sentido, percebemos que o curso de Pedagogia parece não preparar para lidar com as realidades diversas que irão encontrar. Embora haja essa dificuldade em relação ao contato com a sala de aula, Tardif e Raymond (2000, p. 229) afirmam que a "[...] experiência nova proporciona aos professores, progressivamente, certezas em relação ao contexto de trabalho, possibilitando assim a sua integração no ambiente profissional, que são a escola e a sala de aula. Ela vem também confirmar sua capacidade de ensinar".

Em concordância com os autores, podemos afirmar que todo esse sentimento gerado no contato com a sala de aula vem contribuir para a formação da identidade do professor, como também a maneira de lidar com situações adversas, além de perceber que cada aluno tem uma história e que a partir da realidade evidenciada ali deve ser feito um trabalho para melhorar a aprendizagem da criança. A professora Laura afirma que tenta conhecer individualidade dos alunos para conseguir extrair deles formas de melhoria da aprendizagem dos conteúdos matemáticos. Sobre essa questão, os Parâmetros Curriculares Nacionais de Matemática (BRASIL, 1997, p. 29) sugerem que é fundamental ao professor " $[\ldots .$.$] conhecer a história de vida dos$ 
alunos, sua vivência de aprendizagens fundamentais, seus conhecimentos informais sobre um dado assunto, suas condições sociológicas, psicológicas e culturais [...]", dado esse evidente no discurso dessa professora iniciante, uma vez que afirma procurar criar, no espaço da sala de aula, uma relação de confiança para ensinar e aprender conceitos.

Em muitos casos, a forma de conceber a aprendizagem matemática do aluno pode estar ligada à formação que os professores obtiveram em nível inicial nos cursos dos quais são egressos, ou seja, a formação inicial pode apresentar um papel importante quando discute processos de ensino e aprendizagem com os futuros professores e os apresenta formas de organização do trabalho pedagógico com a Matemática. Curi (2005, p. 03) afirma que:

A definição de competências específicas para a educação Matemática dos futuros professores deve ter a finalidade de orientar os objetivos da formação para o ensino de Matemática, a seleção e escolha de conteúdos, a organização de modalidades pedagógicas, dos tempos e espaços da formação, a abordagem metodológica, a avaliação.

Entretanto, no caso pesquisado, não é isso que tem ocorrido. Nessa direção, questionamos as docentes sobre como foi a formação para o ensino de Matemática nos cursos de Pedagogia:

[...] eu achei que foi bem... meio... muito superficial ela só tratava por cima, não teve nada aprofundado por isso é ate que é mais dificultoso hoje trabalha com a matemática porque eu estou vendo agora na prática e então como faz um tempinho que eu terminei a faculdade, então, o conhecimento já não está tão verdinho mais, mas pelo o que eu me lembro que ela trabalhava era muito por cima, muito pincelado. Laura

[...] eu nem me recordo direito do conteúdo de matemática na escola, mais foi através de jogos. O que eu me lembro de Matemática foi através de joguinhos, jogos com formas geométricas, jogos de encaixar, na Pedagogia eu não me lembro do conteúdo da Matemática [...] Emma

Como podemos constatar a formação matemática presente no curso de Pedagogia ainda é um grande problema tanto para quem vai ensinar quanto para quem vai aprender, pois muitas vezes o professor que ministra a disciplina não possui uma trajetória acadêmico-profissional ligada à Educação Matemática, o que, sem dúvidas, pode comprometer o perfil formativo dos futuros professores. Além disso, evidencia-se uma formação centrada em procedimentos metodológicos, apresentação de recursos ligados ao jogo sem uma reflexão do ensino e aprendizagem dos conteúdos matemáticos como objeto da formação docente.

Em outras palavras, o formador responsável pela disciplina de fundamentos do ensino de Matemática precisa abordar, além dos aspectos didáticos, os conteúdos que serão abordados nos primeiros anos de escolarização, uma vez que "[...] os conhecimentos específicos precisam estar articulados à futura prática dessas professoras que irão ensinar matemática [...]" (NACARATO; MENGALI; PASSOS, 2009, p. 36).

Seguindo essa linha raciocínio, Nacarato e Paiva (2006, p. 92) declaram que:

O professor precisa estar em constante formação e processo de reflexão sobre seus objetivos e sobre a conseqüência de seu ensino durante sua formação, na qual ele é o principal protagonista, assumindo a responsabilidade por seu próprio desenvolvimento profissional.

Como observamos que a formação matemática das professoras iniciantes apresentou-se de modo fragmentado enfatizando processos metodológicos sem demonstrar a articulação dos conteúdos com a prática, buscamos compreender como elas estão entendendo os conteúdos e abordando-os com os alunos nas turmas em que lecionam. Para tal, as indagamos sobre as dificuldades na abordagem dos conceitos matemáticos, ou seja, como estão lidando com problemas decorrentes da prática do processo de ensino e aprendizagem.

Laura afirmou que, dentre os conteúdos previstos, se deparou com dificuldade em geometria e relacionou isso com a falta de embasamento na formação inicial "[...] por isso então quando você já tem mais informações a respeito já facilita, por mais que você tenha uma dificuldade leve você relembra o assunto, do conteúdo [...]". Para superação das dificuldades no ensino dos conteúdos ligados à geometria, a professora mencionou recorrer a pesquisas em sites e o acesso a alguns

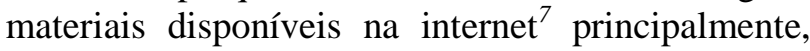
em blogs em que existem atividades já estruturadas, o que não consideramos indicado, haja vista o comprometimento que o acesso às informações 
deturpadas possa gerar na formação do pensamento geométrico dos alunos.

Emma apontou também ter dificuldade à geometria plana, mais especificamente, em simetria "[...] tivemos um conteúdo de simetria ali que (...) apanhei do conteúdo, mas passei assim pelo menos uma noção sabe (...) não consegui entender (...) não superei ainda $[\ldots . .$. ".

Pavanello (2004) enfatiza em sua pesquisa que muitas vezes a formação inicial não tem dado conta de preparar o professor para a tarefa de ensinar geometria e aponta para o abandono do ensino de dessa área do conhecimento matemático. Para a autora:

As dificuldades de professores no reconhecimento de figuras geométricas planas, de seus elementos e propriedades, e, portanto, em atividades de classificação, indicam que o trabalho pedagógico realizado com eles nas diferentes instâncias de sua formação não lhes permitiu elaborar devidamente seus conceitos de figuras planas (PAVANELLO, 2004, p. 135).

Ainda sobre as dificuldades na abordagem dos conteúdos geométricos, Vasconcellos (2008, p. 83) afirma:

[...] os professores ainda não têm a devida compreensão acerca deste assunto. Em função disso, comprometem o desenvolvimento dos alunos por priorizarem, na escola, o trabalho com figuras geométricas sem o estabelecimento de relações entre elas e o espaço no qual estão inseridas.

Nesse contexto, podemos inferir que as professoras iniciantes participantes dessa pesquisa possuem dificuldades em compreender os conteúdos pelo pouco tempo que é disponibilizado à abordagem conceitual dos conteúdos no curso de licenciatura e em como os conteúdos específicos são trabalhados, o que nesse caso não foram objeto de formação, pois ambas declararam não ter contato com as áreas do conhecimento matemático durante a formação inicial.

Nono e Mizukami (2006, p.11) evidenciam que há uma crença de que o domínio do conteúdo específico "[...] pode ser alcançado durante o exercício da docência, sempre que a prática solicitar". Entretanto, não é isso que vem ocorrendo, o professor com defasagem na formação para o ensino de Matemática acaba carregando esse problema ao longo da vida docente e, por vezes, transfere os equívocos conceituais para a formação de seus alunos.

Outra dificuldade presente na construção do início da docência nas aulas de Matemática apresentou-se no discurso das professoras na utilização dos materiais concretos. Ambas afirmaram não saber utilizar o ábaco, o material dourado e blocos lógicos nas aulas e a justificativa para isso deve-se, com base na fala delas, à formação inicial que não lhes apresentou tais recursos.

Nacarato (2005, p.03) esclarece que a dificuldade presente na utilização do concreto "[...] diz respeito a sua não relação com os conceitos que estão sendo trabalhados". Ou seja, de nada adiantará levar algo concreto para a sala de aula se há dificuldades de relacionar às vivências cotidianas e isso não se aprende na prática, é preciso um entendimento, por parte dos professores que ensinam Matemática, para que auxiliem os alunos a fazer a relação entre o concreto e o abstrato e isso não ocorrerá na exploração esporádica desses recursos.

Dessa maneira, Bittar e Freitas (2005, p. 29) afirmam ser "[...] também importante observar que o uso de material concreto não dispensa em modo algum a passagem para o abstrato, e é justamente essa passagem que deve ser cuidadosamente planejada pelo professor". Muitas vezes essa transição não é planejada, o que acaba não fazendo sentido ao aluno, o material concreto exige uma mediação do professor e ele deve saber como trabalhar e em que momento mediar o conhecimento. Spinillo e Magina (2004, p. 20) colocam que "[...] o material concreto não é utilizado de maneira que venha auxiliar as crianças na correção de seus erros [...]", pois da forma que está sendo trabalhado não leva a ter um pensamento que transita do concreto para o abstrato.

Nacarato, Mengali e Passos (2009, p. 32) advogam que "[...] as professoras polivalentes, em geral, foram e são formadas em contextos com pouca ênfase em abordagens que privilegiem as atuais tendências presentes nos documentos curriculares". Chamamos atenção para o fato de que o conhecimento tanto em geometria quanto da utilização dos materiais concretos para o ensino de Matemática é fundamental para a prática pedagógica e precisam ser abordados na formação inicial dos professores, logo, é de reconhecer que não será nada fácil construir uma cultura de trabalho pedagógico que os incorpore nas aulas se nem o professor sabe como fazer.

Emma e Laura ainda apontaram como um 
terceiro obstáculo à questão da cobrança do sistema educacional, dificuldade essa que tem gerado grande preocupação por parte dessas professoras iniciantes, pois os prazos para cumprir datas de fechamento de conteúdos, avaliações e diários de classes apresentam-se como um desafio.

Souza (2009, p.37) considera que no espaço escolar, "[...] geralmente, o professor novato fica à mercê da sorte, podendo ou não conseguir superar a fase das adaptações que está confrontando.” Essa fase de adaptação pode estar ligada ao tempo de ou cobrança do sistema, como vimos, tendo em vista que os professores precisam cumprir o cronograma de matérias propostas para as turmas que lecionam.

Os dados analisados nessa experiência de pesquisa com professoras iniciantes revelam que muitos são os desafios presentes na constituição da prática pedagógica nas aulas de Matemática nos primeiros anos da docência. Dentre eles, os mais alarmantes referem-se à abordagem dos conteúdos geométricos e a utilização de materiais concretos no desenvolvimento dos conteúdos matemáticos propostos para ano escolar em que atuam.

Por fim, os problemas do processo de ensino e abordagem dos conteúdos em que as professoras iniciantes mencionaram ter dificuldades é fruto da forma como os mesmos foram abordados no curso de Pedagogia, razão pela qual defendemos o posicionamento de que a formação para o ensino de Matemática dos professores polivalentes precisa levar em consideração os conhecimentos específicos e as formas aplicação de suas propriedades para que consigam contribuir com a construção do pensamento matemático dos alunos.

\section{Considerações finais}

Os resultados do estudo indicaram que as professoras egressas do curso de Pedagogia percebem que a identidade profissional é construída ao longo da experiência pedagógica e que o conhecimento não é estático, há sempre algo novo que possa ser aprendido. Essa realidade nos leva a afirmar que a fase de entrada na carreira é um momento delicado e de aprendizagens intensas, o que aponta para uma necessária articulação entre a transição da formação inicial e ingresso na profissão.

Com a pesquisa verificamos que as professoras se identificaram com a docência ao longo do curso de Pedagogia e que a inserção no mercado de trabalho nessa área foi tardia tendo em vista a instabilidade profissional, gerada pelos processos seletivos de contratação de docentes e até mesmo por medo do desconhecido. Ilustra essa afirmativa $o$ fato de que ambas vivenciaram momentos de: a) medo de se inserir na carreira; b) falta de apoio pedagógico; c) dificuldade em compreender os conteúdos ligados à geometria e na utilização de materiais concretos e; d) relacionamento com colegas mais experientes.

Ainda com base nos estudos, conseguimos identificar que elas parecem se preocupar com a aprendizagem de seus alunos e que procuram superar suas dificuldades didático-pedagógicas a partir de tentativas de ensinar aquilo que nem sempre aprenderam no curso de licenciatura: os conteúdos matemáticos específicos. Contudo, chamamos atenção para o fato de que de nada adiantará a boa vontade se o professor não se apropriar do conhecimento específico do conteúdo, uma vez que para se ensinar Matemática ele precisa compreender os componentes curriculares que são a base para o ensino dessa área.

Assim, compete à formação continuada auxiliar essas docentes na forma de organização do trabalho pedagógico e na compreensão dos conteúdos matemáticos que terão de ensinar ao longo da carreira, uma vez que elas já estão em exercício profissional. Nessa direção, concebemos o espaço da formação contínua como sendo aquele mediado pela reflexão sobre a prática pedagógica e que vá ao encontro das necessidades formativas do professor.

O contato com a ementa da disciplina de formação para o ensino de Matemática possibilitounos a compreensão de que essa se restringe mais aos procedimentos metodológicos e pouco aborda os conteúdos que o professor terá de ensinar, o que, sem dúvidas, reflete no perfil do profissional que ingressa na carreira.

Uma tentativa de reverter esse quadro talvez possa apresentar-se no investimento de políticas públicas voltadas para a experiência de mentoria existente em Portugal, onde o docente iniciante tem um tutor que auxilia na construção de sua carreira, o que em nosso país infelizmente não ocorre.

Os resultados finais da pesquisa indicam uma grande lacuna no que se refere à fase de inserção na docência e as necessidades formativas dos professores novatos, ou seja, é preciso um movimento que encare o início da docência como um projeto coletivo no sentido de contribuir tanto para a identidade desses sujeitos quanto para a permanência na profissão. 


\section{Notas}

1 Especificamente os cursos de Pedagogia (CURI, 2004).

$2 \mathrm{Na}$ literatura existem divergências com relação à denominação desse momento, logo, em uma ampla leitura acerca da temática podemos observamos autores que o denominam como "choque com a realidade", "choque de realidade", "choque da realidade" e/ou "choque com o real".

3 Por meio de tutorias em que professores experientes acompanham professores novatos no período do estágio probatório em ações formativas.

4 Curi (2004); Nacarato, Mengali e Passos (2009); Vasconcellos (2009).

5 As duas professoras iniciantes são egressas do mesmo curso de Pedagogia e, portanto, tiveram a mesma formação.

6 Contudo, isso mudou a partir do ano de 2014, momento em que a figura desse profissional deixou de existir no espaço escolar por contenção de gastos do governo.

7 Os sites mencionados pela professora não foram sites de universidades em que poderíamos ter um respaldo maior dos direcionamentos pedagógicos e isso reforça nossa afirmativa: a de que a procura livre por caminhos na internet nem sempre auxilia na abordagem dos conteúdos matemáticos de forma mais adequada.

\section{Referências}

BEDNARCHUK, J. Z. Formação inicial em matemática: as manifestações dos egressos de pedagogia sobre a formação para a docência nos anos iniciais do Ensino Fundamental. 2012. 172 p. Dissertação (Mestrado em Educação) Universidade Estadual de Ponta Grossa, 2012.

BOGDAN, R.; BIKLEN, S. Investigação qualitativa em educação: uma introdução à teoria $\mathrm{e}$ aos métodos. Porto, Porto Editora, 1994.

BRASIL. Ministério da Educação. Secretaria de Educação Fundamental. Parâmetros Curriculares Nacionais: Matemática $\left(1^{\circ}\right.$ e $2^{\circ}$ ciclos do ensino fundamental). v. 3. Brasília: MEC, 1997.

BITTAR, M. FREITAS, J.L.M. Fundamentos $e$ metodologia de matemática para os ciclos iniciais do ensino fundamental. Editora UFMS. Edição 2. Campo Grande - MS, 2005.

CERQUETTI-ABERKANE, F.; BERDONNEAU, C. O ensino da matemática na educação infantil. Tradução Eunice Gruman. Porto Alegre: Artes Médicas, 2001.

CIRÍACO, K. T.; TEIXEIRA L. R. M. Elementos constitutivos da prática pedagógica nas aulas de Matemática: os saberes adquiridos nos cursos de formação inicial em pedagogia. Revista Paranaense de Educação Matemática, Campo Mourão, Pr, v.3, n.5, jul.-dez. p. 157-179. 2014. Disponível em: $<$ http://www.fecilcam.br/rpem/documentos/v3n5/Ar tigo_7.pdf $>$, Acesso em: 12, mar. 2015.

CURI, E.; PIRES. C.M.C. Pesquisas sobre a formação de professor que ensina matemática por grupos de pesquisa de instituições paulistanas. Educação Matemática Pesquisa, São Paulo, v. 10, n. 1, p. 151-189, 2008. Disponível em: <http://revistas.pucsp.br/index.php/emp/article/view File/1655/1065>, Acesso em: 10. fev, 2015.

CURI, E. Formação de professores polivalentes: uma análise de conhecimentos para ensinar Matemática e de crenças e atitudes que interferem na constituição desses conhecimentos. 2004, 278 p. Tese (Doutorado em Educação Matemática). Pontifícia Universidade Católica de São Paulo. PUC/SP, 2004.

A formação matemática de professores dos anos iniciais do ensino fundamental face às novas demandas brasileiras. Revista Iberoamericana de Educación. p. 01-10. 2005. Disponível em: <http://www.rieoei.org/deloslectores/1117Curi.pdf> , Acesso em: 03, mar. 2015.

DANTE, L. R. Didática da resolução de problemas de matemática: $1^{\mathrm{a}}$ a $5^{\mathrm{a}}$ séries. 12. ed. São Paulo: Ática, 2000.

FRANCO, F. C. O coordenador pedagógico e o professor iniciante. In: __ ALMEIDA, L.R. BRUNO, E. B. C; CHRISTOV, L.H. da S. $O$ coordenador pedagógico e a formação docente. São Paulo: Loyola, 2000. p. 33-48.

FREITAS, M.N.C. O professor iniciante e suas 
estratégias de socialização profissional. 2000. 123 p. Dissertação (Mestrado em Educação) Pontifícia Universidade Católica do Rio de Janeiro - PUC/RJ, 2000.

GATTI. B. A. Formação de Professores no Brasil: características e problemas. Educação \& Sociedade, Campinas, v. 31, n. 113, p. 1355-1379, out.-dez. $2010 . \quad$ Disponível em: http://www.scielo.br/pdf/es/v31n113/16.pdf, Acesso em: 12, jan. 2015.

GOMES, M. G. Obstáculo epistemológicos, obstáculos didáticos e o conhecimento Matemático nos cursos de formação de Professores das séries iniciais no Ensino Fundamental. Contrapontos - ano 2 - n. 6 - p. 423-437 - Itajaí, set./dez. 2002. Disponível em: <http://www6.univali.br/seer/index.php/rc/article/vi ew/181>, Acesso em: 13, mar. 2015.

Obstáculos na aprendizagem matemática: identificação e busca de superação nos cursos de formação de professores das séries iniciais. 2006. 161 p. Tese (Doutorado em Educação Científica e Tecnológica) Universidade Federal de Santa Catarina. Florianópolis, 2006.

GUARNIERI, M. R. Tornando-se professor: o início na carreira docente e a consolidação da profissão. 1996. 153 p. Tese (Doutorado em Educação). Universidade Federal de São Carlos: UFSCar, 1996.

HUBERMAN, M. O ciclo de vida profissional dos professores.In: NÓVOA, A. Vidas de professores. Porto, Portugal: Porto, 1995, p. 31-61.

KAMII, Constance. A criança e o número. Campinas: Papirus, 1984.

LIMA, E. F. Começando a ensinar: começando a aprender? Tese (Doutorado em Educação). 1996, 153 p. Universidade Federal de São Carlos: UFSCar, 1996.

LÜDKE, M.; ANDRÉ, M. E. D. A. Pesquisa em educação: abordagens qualitativas. São Paulo: EPU, 1986.

MANZINI, E. J. A entrevista na pesquisa social. Didática, São Paulo, v. 26/27, p. 149-158,
1990/1991.

MARCELO GARCÍA, C. O professor iniciante, a prática pedagógica e o sentido da experiência. Revista Brasileira de Pesquisa sobre Formação Docente. Belo Horizonte: Autêntica v. 02, n. 03, p. 11-49, ago./dez. 2010. Disponível em: $<$ http://formacaodocente.autenticaeditora.com.br/art igo/exibir/8/18/1>, Acesso em: 25, abr. 2015.

MARIANO, A. L. S. A aprendizagem da docência no início da carreira: Qual política? Quais problemas? Revista Exitus. Volume 02. $\mathrm{N}^{\mathrm{o}}$ 01, Jan./Jun. 2012, p. 79-94. Disponível em: http://www.ufopa.edu.br/revistaexitus/revistas/volu me-ii/artigos/a-aprendizagem-da-docencia-no-inic io-da-carreira-qual-politica-quais-problema s/view. Acesso em: 03, abr. 2015.

NACARATO, A. M. Eu trabalho primeiro no concreto. Revista de Educação Matemática - Ano 9, Nos. 9-10 (2004-2005). p. 01-06. Disponível em: $<$ https://flautas.files.wordpress.com/2010/10/eu-trab alho-primeiro-no-concreto.pdf $>$, Acesso em: 06, mai. 2015.

NACARATO, A. M.; MENGALI, B. L. da S.; PASSOS, C. L. B. A matemática nos anos iniciais do ensino fundamental: tecendo fios do ensino e do aprender. Belo Horizonte: Autêntica Editora, 2009.

NACARATO. A. M.; PAIVA, M. A. A formação de professor que ensina matemática: perspectivas pesquisas. Belo Horizonte: Autêntica, 2006.

NARACATO, A. M.; PASSOS, C. L. B.; CARVALHO, D. L. de. Os graduandos em pedagogia e suas filosofias pessoais frente à matemática e seu ensino. Zetetiké. Campinas, Unicamp/FE/CEMPEM, v. 12, n.21, jan/jun 2004. p. 09-34. Disponível em: <https://www.fe.unicamp.br/revistas/ged/zetetike/ar ticle/view/2471>, Acesso em: 18, jun. 2015.

NACARATO, A. M.; LOPES, C. A. E. (Orgs.). Escritas e leituras na educação matemática. Belo Horizonte: Autêntica, 2005.

NONO, M. A.; MIZUKAMI, M. da G. N. Professoras iniciantes e ensino de conteúdos matemáticos. Contrapontos - volume 6 - Itajaí, mai/ago 2006. p. 339-356. Disponível em: 
http://www6.univali.br/seer/index.php/rc/article/vie w/869, Acesso em: 08, fev. 2015.

PANIZZA, M. Ensinar matemática na educação infantil e nas séries iniciais: análise e propostas. Porto Alegre: Artmed, 2006.

PAVANELLO, R. Formação de professores e dificuldades de aprendizagem em Matemática. In: MACIEL, L. S. B.; PAVANELLO, R.; MORAES, S. P. G. de (Orgs.). Formação de professores $e$ prática pedagógica. Maringá: Eduem, 2002, p. 127142.

PAVANELLO, R. M. (org.) Matemática nas séries iniciais do ensino fundamental: a pesquisa e a sala de aula. Biblioteca do Educador Matemático. São Paulo: SBEM, 2004.

PIMENTA, S. G. (org.). Didática, currículo $e$ saberes escolares. Rio de janeiro. DP\&A Editora. 2005.

SPINILLO, A. G. MAGINA. S. Alguns 'mitos' sobre a educação matemática e suas conseqüências para o ensino fundamental. In: PAVANELLO, R (org.) Matemática nas séries iniciais do ensino fundamental: a pesquisa e a sala de aula. Volume 2. Biblioteca do educador Matemático. São Paulo, 2004, p. 17-38.

SMOLE, K. C. S. A matemática na educação infantil: a teoria das inteligências múltiplas na prática escolas. Porto Alegre: Artmed, 2003.

SILVEIRA, M.F.L. Trabalhando pelo sucesso escolar: as vivências de uma professora em seu primeiro ano de atuação na escola pública. 2002, 168 p. Dissertação (Mestrado em Educação). Universidade Federal de São Carlos - UFSCar, 2002.

SOUZA, D. B. de. Os dilemas do professor iniciante: reflexões sobre os cursos de formação. Revista Multidisciplinar da Uniesp Saber Acadêmico - n ${ }^{\circ} 08$ - Dez. 2009. p. 35-45.
Disponível

em: $<$ http://www.uniesp.edu.br/revista/revista8/pdf/artig os/04.pdf>, Acesso em: 05, mar. 2015.

SHULMAN, L. S. Knowledge and teaching: foundations of the new reform. Harvard Educational Review, 57 (1), 1987, p. 10-33.

TARDIF, M. Saberes docentes e formação profissional. $8^{\text {a }}$ edição Petrópolis, RJ: Vozes, 2007.

TARDIF, M.; RAYMOND. D. Saberes, tempo e aprendizagem do trabalho no magistério. Educação \& Sociedade, ano XXI, no 73, Dezembro/2000, p. 209-244. Disponível em: $<$ http://www.scielo.br/pdf/es/v21n73/4214>, Acesso em: 25, mai. 2015.

VALLE, I.R. Carreira do magistério: uma escolha profissional deliberada. Revista Brasileira de Estudos Pedagógicos. Brasília, v.87, n.216, p.178187, maio/ago.2006. Disponível em: <http://rbep.inep.gov.br/index.php/RBEP/article/vie wFile/32/34>, Acesso em: 12, mar. 2015.

VASCONCELLOS, M. de O. F. Formação docente e entrada na carreira: uma análise dos saberes mobilizados pelos professores que ensinam matemática nos anos iniciais. 2009, p. 209. Tese (Doutorado em Educação). Universidade Federal de Mato Grosso do Sul. Centro de Ciências Humanas e Sociais. Campo Grande/MS, 2009.

A diferenciação entre figuras geométricas não planas e planas: o conhecimento dos alunos das séries iniciais do ensino fundamental e o ponto de vista dos professores. ZETETIKÉ Cempem - FE - Unicamp - v. 16 - n. 30 - jul./dez. - 2008, p. 77-106. Disponível em: <https://www.fe.unicamp.br/revistas/ged/zetetike/ar ticle/view/2516>, Acesso em: 30, abr. 2015.

VEENMAN, S. Problemas percebidos de professores iniciantes. Review of educatinal Research, v. 54, n.2. 1984, p. 39-68.

\section{Sobre os autores}

Klinger Teodoro Ciríaco: Professor Adjunto do Curso de Pedagogia da Fundação Universidade Federal de Mato Grosso do Sul - UFMS, Câmpus Naviraí; Doutor em Educação pela UNESP, Presidente Prudente/SP. 
Gislaine Aparecida Puton Zortêa: Mestranda em Ensino e Processos pela Universidade Estadual Paulista Júlio de Mesquita Filho - UNESP/IBILCE/InterUnidades - na linha de pesquisa "Educação Matemática"; Licenciada em Pedagogia pela UFMS.

Recebido em setembro de 2015.

Aprovado em janeiro de 2016. 